\title{
Sarcopenia is an Independent Risk Factor for Postoperative Blood Transfusion in Total Knee Arthroplasty: A Retrospective, Propensity Score- Matched Cohort Study
}

\section{Doohyun Hwang}

Seoul National University College of Medicine

Hyuk-Soo Han

Seoul National University Hospital

Myung Chul Lee

Seoul National University Hospital

Du Hyun Ro ( $\sim$ duhyunro@gmail.com )

Seoul National University Hospital

\section{Research Article}

Keywords: Sarcopenia, Total knee arthroplasty, Transfusion, Bioelectrical impedance analysis, Complication, Skeletal muscle index

Posted Date: January 7th, 2022

DOI: https://doi.org/10.21203/rs.3.rs-1211390/v1

License: (c) (1) This work is licensed under a Creative Commons Attribution 4.0 International License.

Read Full License 


\section{Abstract}

Background: Sarcopenia, an age-related loss of skeletal muscle mass and function, is correlated with adverse outcomes after some surgeries. This study examined the incidence and characteristics of sarcopenic patients undergoing primary total knee arthroplasty (TKA), and identified sarcopenia as an independent risk factor for postoperative TKA complications.

Methods: A retrospective cohort study examined 452 patients who underwent TKA. The skeletal muscle index (SMI) was obtained via bioelectrical impedance analysis (BIA), along with demographics, the Charlson Comorbidity Index, and medication, laboratory and operative data for 2018-2021. Patients were categorized into non-sarcopenia $(n=417)$ and sarcopenia $(n=35)$ groups using the SMI cut-off suggested by the Asian Working Group for Sarcopenia 2019 (males, $<7.0 \mathrm{~kg} / \mathrm{m}^{2}$; females, $<5.7 \mathrm{~kg} / \mathrm{m}^{2}$ ). Three postoperative complications were analyzed: blood transfusion, delirium, and acute kidney injury (AKI). Baseline characteristics were propensity score-matched to address potential bias and confounding factors.

Results: The incidence of sarcopenia in primary TKA was 7.7\% (35/452). The sarcopenia group had a lower preoperative hemoglobin $(12.18 \pm 1.20 \mathrm{vs} .13 .04 \pm 1.73 \mathrm{~g} / \mathrm{dL}, p=0.004)$ and total protein $(6.73 \pm 0.42$ vs. $7.06 \pm 0.44 \mathrm{mg} / \mathrm{dL}, p=0.001)$. Propensity scoring matching and logistic regression showed that more patients in the sarcopenia group received postoperative blood transfusions (OR $=6.60,95 \% \mathrm{Cl}$ : $1.57-$ $45.5, p=0.021)$; there was no significant difference in AKI or delirium. Univariate receiver operating characteristic curve analysis of the propensity-matched group, to determine the predictive value of SMI for postoperative transfusion, gave an AUC of $0.797(0.633-0.96)$ and SMI cut-off of $5.6 \mathrm{~kg} / \mathrm{m}^{2}$.

Conclusions: Sarcopenia determined by BIA was an independent risk factor for postoperative transfusion in TKA. Multifrequency BIA can serve as a screening tool for sarcopenia. Orthopedic surgeons should be aware of this, as it could influence the decision-making process or treatment plan of patients with sarcopenia undergoing primary TKA.

Level of evidence: III, retrospective cohort study

\section{Background}

Total knee arthroplasty (TKA) is effective for treating severe degenerative arthritis of the knee, relieving pain and restoring mobility $[1,2]$. TKA greatly enhances social and physical functioning, and thus the overall quality of life. As the population ages, the demand for TKA is increasing rapidly [3-5]. Despite its benefits, TKA involves substantial blood loss and approximately one-third of patients receive postoperative transfusions [6, 7]. Allogeneic transfusion is necessary for hemodynamic stability, but has side effects such as an increased risk of deep vein thrombosis, deep surgical site infection, and mortality, which adversely affect patient outcomes [8-12]. 
As the demand for TKA increases, patient selection and an understanding of the risk factors for postoperative transfusion should be emphasized. Many studies have evaluated the correlations between risk factors and complications of TKA, including postoperative blood transfusion, yet few studies have explored the effects of sarcopenia on complications of TKA [11, 13-15].

Sarcopenia was first characterized as an age-related loss of skeletal muscle mass [16]. As our understanding of sarcopenia has improved, it has been defined in various ways and attracted increasing academic interest [16-24]. The European Working Group on Sarcopenia in Older People defines sarcopenia as a "syndrome of progressive and generalized loss of skeletal muscle mass and strength, with a risk of adverse outcomes such as physical disability, poor quality of life and death" [25]. The reported prevalence of sarcopenia varies widely depending on the study population, and the prevalence in patients undergoing orthopedic surgery appears to be higher than in the general population. Several studies have demonstrated that sarcopenia independently predicts adverse outcomes in patients undergoing general surgery, but there have been few reports on the impact of sarcopenia on orthopedic surgery, including TKA $[26,27]$.

One validated method for assessing skeletal muscle mass is multifrequency bioelectrical impedance analysis (BIA) $[21,25]$. This uses a combination of low and high frequencies of alternating current to calculate intercellular, extracellular, and total body water by measuring impedance (tissue resistance and reactance) as current passes through the body [28]. It is an attractive method for clinically identifying sarcopenic patients because it is affordable, non-invasive and can be completed in minutes [19]. BIA has been used extensively to assess sarcopenia in oncology [29]. It appears even more suitable for evaluating sarcopenia in orthopedics, because radiological assessments such as magnetic resonance imaging, computed tomography, and dual-energy X-ray absorptiometry (DEXA) are not always available for these patients.

Although sarcopenia is attracting increasing attention, few orthopedic studies have examined its impact. Sarcopenia is associated with increased morbidity and mortality in several surgical fields, and this study evaluated the impact of sarcopenia on TKA patients. We hypothesized that sarcopenia, as measured by BIA, correlates with an increased risk of postoperative blood transfusion, and that muscle mass quantity can predict blood transfusion after TKA. This study reports the incidence and characteristics of sarcopenia patients undergoing primary TKA, and evaluates the correlation between sarcopenia and blood transfusion after TKA.

\section{Methods}

\section{Study subjects}

After obtaining Institutional Review Board approval (IRB No. 1806-185-961), we conducted a retrospective, single-center study. From May 2018 to April 2021, patients scheduled for primary TKA to treat degenerative knee arthritis were enrolled after providing informed consent. Subjects with adequate 
preoperative BIA, as determined using the InBody S10 device (InBody Co. Ltd., Seoul, Korea) were reviewed. Initially, 633 patients were enrolled. Patients who underwent simultaneous bilateral TKA $(n=5)$ or had inadequate tissue hydration $(n=175)$ or severe obesity [body mass index $(\mathrm{BMI})>35 \mathrm{~kg} / \mathrm{m}^{2} ; n=1$ ] were excluded [19, 21, 30], such that 452 patients (60 males, 392 females) were included in the final analysis.

\section{Operative technique and rehabilitation after TKA}

Antiplatelet agents, including aspirin, clopidogrel, warfarin, heparin, and factor Xa inhibitors, were discontinued 1 week before surgery. The primary TKAs were performed in the identical manner. After midline skin incision, arthrotomy was performed with a parapatellar approach. An intramedullary guide was used to cut the femur and an extramedullary guide was used to cut the tibia. The intramedullary femoral canal was sealed with an autologous bone plug, with all implants being fixed with bone cement. After suturing the joint capsule, $1 \mathrm{~g}$ of tranexamic acid (TXA) was administered, unless contraindicated. All patients followed the same rehabilitation protocol, including full weight bearing gait and continuous passive motion (CPM) beginning 1 day after surgery. Ambulation was allowed 6 hours after surgery [11, 31].

\section{Data collection}

All data were collected from the institutional electronic medical records. Sarcopenia was defined using the cutoffs for the appendicular skeletal muscle index (SMI) suggested by the Asian Working Group for Sarcopenia 2019 (males, $<7.0 \mathrm{~kg} / \mathrm{m}^{2}$; females, $<5.7 \mathrm{~kg} / \mathrm{m}^{2}$ ) [21]. SMl is defined as the height-adjusted appendicular skeletal muscle mass (ASM) and is calculated via BIA. The baseline characteristics of the sarcopenia and non-sarcopenia groups were compared.

Patient demographics, comorbidities (modified Charlson Comorbidity Index [mCCl] and American Society of Anesthesiologists [ASA] score), medication history, and laboratory and operative data were collected. The $\mathrm{mCCl}$ was calculated by summing the weighted scores for individual comorbidities [32].

Three postoperative events were analyzed: blood transfusion, delirium, and acute kidney injury (AKI). The transfusion group was defined as patients whose hemoglobin $(\mathrm{Hb})$ levels dropped to less than $7 \mathrm{~g} / \mathrm{dL}$ within 2 weeks after the first TKA [11]. Acute kidney injury was defined using the serum creatinine criteria of the Kidney Disease-Improving Global Outcomes group [33]. The Diagnostic and Statistical Manual of Mental Disorders, Fifth Edition defines the key feature of delirium as a disturbance in attention and awareness accompanied by an acutely fluctuating mental state [34].

\section{Statistical analysis}

The statistical analyses were performed using RStudio for Windows (ver. 1.2.5033; RStudio, Boston, MA, USA). Nominal data are shown as percentages and were analyzed with a two-sided Pearson's $\chi^{2}$ test or Fisher's exact test. Continuous data are shown as the mean $\pm S D$ and were analyzed using Student's $t$ test. Statistical significance was determined at $p<0.05$. Simple binary logistic regression analysis was 
used to assess postoperative complications, and odds ratios (ORs) and 95\% confidence intervals (Cls) were calculated.

To address potential bias and confounding factors, rigorous adjustment was conducted using 1:1 propensity score-matching (nearest neighbor matching). Propensity scores were estimated from multiple logistic regression analyses including all relevant covariates. The matching criteria were age at surgery, sex, $\mathrm{BMI}, \mathrm{mCCl}$, type of surgery, TXA use, preoperative $\mathrm{Hb}$, preoperative platelets, and preoperative protein. After matching, 35 patients remained in each group (Table 1). Adjusted $p$-values and ORs were calculated for postoperative complications after propensity score-matching (Table 2).

\section{Results}

Table 1. Baseline characteristics of the propensity score-matched sarcopenia and non-sarcopenia groups. 
Total population

$(N=452)$

Sarcopenia

Characteristics

Yes No
Age at surgery, years

(SD)

Sex (\%)

Female

Male

$\mathrm{BMI}, \mathrm{kg} / \mathrm{m}^{2}$ (SD)

$\mathrm{mCCl}$

\begin{tabular}{l}
\hline 0 \\
\hline 1 \\
2 \\
$\geq 3$ \\
\hline Type of surgery (\%) \\
\hline Unilateral (\%) \\
\hline Bilateral (\%) \\
\hline Tranexamic acid (\%) \\
$\begin{array}{l}\text { Hemoglobin, } \mathrm{g} / \mathrm{dL}(\mathrm{S} \\
\text { Platelet count } \times / 10^{9} \\
\text { (SD) }\end{array}$ \\
$\begin{array}{l}\text { Total protein, } \mathrm{mg} / \mathrm{dL} \\
\text { (SD) }\end{array}$
\end{tabular}

$5(14.3)$

$6.7(0.4)$ $(n=35)$

35

$74.5(6.5)$

$33(94.3)$

2 (5.7)

$23.9(3.4)$

$(n=417)$

417

70.5 (6.6)

58 (13.9)

$26.7(3.2)$
Propensity-matched population

$(N=70)$

Sarcopenia

Yes No $p$

$(n=35) \quad(n=35)$

35

74.51

(6.46)

74.19

(6.69)

35

value

0.001

$$
(6.46)
$$

$359(86.1) \quad 0.266$

33 (94.3)

33 (94.3)

1

2 (5.7)

$2(5.7)$

23.9 (3.4)

24.1 (2.6)

0.691

$<0.001$

0.462

0.537

$15(42.9) \quad 16(45.7)$

12 (34.3) 8 (22.9)

3 (8.6)

2 (5.7)

5 (14.3)

9 (25.7)

74 (17.7)

0.486

1

$20(57.1) \quad 211(50.6) \quad 20(57.1) \quad 20(57.1)$

$15(42.9) \quad 206(49.4) \quad 15(42.9) \quad 15(42.9)$

$\begin{array}{llllll}31(88.6) & 390(93.5) & 0.286 & 31(88.6) & 29(82.9) & 0.733\end{array}$

$\begin{array}{llllll}12.2(1.2) & 13.0(1.7) & 0.004 & 12.2(1.2) & 12.2(0.9) & 0.830 \\ 248.2 & 239.8 & 0.402 & \begin{array}{l}248.2 \\ (54.1)\end{array} & \begin{array}{l}259.9 \\ (60.5)\end{array} & 0.400 \\ (54.1) & (57.7) & & (5.1) & \end{array}$

$7.1(0.4) \quad<0.001$

$6.7(0.4)$

$6.8(0.5)$

0.753

Values are shown as the mean \pm standard deviation or number (\%). Statistical significance was set at $p<0.05$

BMI, body mass index; $\mathrm{mCCl}$, modified Charlson Comorbidity Index 
The proportion of patients who had undergone primary TKA and had sarcopenia was 7.7\% (35/452). Comparing the sarcopenia and non-sarcopenia groups, there were significant differences in age at surgery, weight, height, BMI, preoperative $\mathrm{Hb}$, and preoperative total protein (Table 1). The patients with sarcopenia were older $(74.5 \pm 6.5$ vs. $70.5 \pm 6.6$ years, $p=0.001)$ and had a lower BMI $(23.9 \pm 3.4 v s .26 .7$ $\left.\pm 3.2 \mathrm{~kg} / \mathrm{m}^{2}, p<0.001\right)$, preoperative Hb level $(12.2 \pm 1.2 \mathrm{vs} .13 .0 \pm 1.7 \mathrm{~g} / \mathrm{dL}, p=0.004)$, and total protein level $(6.7 \pm 0.4$ vs. $7.1 \pm 0.4 \mathrm{mg} / \mathrm{dL}, p<0.001)$. The detailed information on the patients' demographic characteristics and laboratory data in this study can be found in Supplementary Table 1 and Table 2, respectively.

Table 2 Comparison of postoperative complications between the sarcopenia and non-sarcopenia groups.

\begin{tabular}{|c|c|c|c|c|c|c|c|c|}
\hline \multirow[b]{3}{*}{ Characteristics } & \multicolumn{4}{|c|}{$\begin{array}{l}\text { Total population } \\
(N=452)\end{array}$} & \multicolumn{4}{|c|}{$\begin{array}{l}\text { Propensity-matched } \\
\text { population }(N=70)\end{array}$} \\
\hline & \multicolumn{4}{|c|}{ Sarcopenia } & \multicolumn{4}{|c|}{ Sarcopenia } \\
\hline & $\begin{array}{l}\text { Yes } \\
(n \\
=35)\end{array}$ & $\begin{array}{l}\text { No } \\
(n \\
=417)\end{array}$ & $\begin{array}{l}p- \\
\text { value }\end{array}$ & $\begin{array}{l}\text { OR } \\
(95 \% \\
\mathrm{Cl})\end{array}$ & $\begin{array}{l}\text { Yes } \\
(n=35)\end{array}$ & $\begin{array}{l}\text { No } \\
(n \\
=35)\end{array}$ & $\begin{array}{l}p- \\
\text { value }\end{array}$ & $\begin{array}{l}\mathrm{OR} \\
(95 \% \mathrm{Cl})\end{array}$ \\
\hline Transfusion (\%) & $\begin{array}{l}10 \\
(28.6)\end{array}$ & $\begin{array}{l}51 \\
(12.2)\end{array}$ & 0.009 & $\begin{array}{l}2.87 \\
(1.25 \\
6.17)\end{array}$ & $\begin{array}{l}10 \\
(28.6)\end{array}$ & $2(5.7)$ & 0.021 & $\begin{array}{l}6.60 \\
(1.57, \\
45.5)\end{array}$ \\
\hline $\begin{array}{l}\text { Acute Kidney } \\
\text { Injury (\%) }\end{array}$ & $\begin{array}{l}1 \\
(2.9)\end{array}$ & $\begin{array}{l}50 \\
(12.0)\end{array}$ & 0.14 & $\begin{array}{l}0.22 \\
(0.01 \\
1.04)\end{array}$ & $1(2.9)$ & $\begin{array}{l}6 \\
(17.1)\end{array}$ & 0.079 & $\begin{array}{l}0.14 \\
(0.01 \\
0.90)\end{array}$ \\
\hline Delirium (\%) & $\begin{array}{l}4 \\
(11.4)\end{array}$ & $\begin{array}{l}19 \\
(4.6)\end{array}$ & 0.087 & $\begin{array}{c}2.70 \\
(0.75 \\
7.74)\end{array}$ & $4(11.4)$ & $2(5.7)$ & 0.4 & $\begin{array}{l}2.13 \\
(0.39 \\
16.1)\end{array}$ \\
\hline
\end{tabular}

Values are presented as the mean \pm standard deviation or number (\%). Statistical significance was set at $p<0.05$.

Three postoperative complications were analyzed using simple binary logistic regression. More patients in the sarcopenia group received postoperative blood transfusions $(28.6 \mathrm{vs} .12 .2 \%, \mathrm{OR}=2.87,95 \% \mathrm{Cl}$ : $1.25-6.17, p=0.009$ ) (Table 2). However, there was no difference in the incidence of AKI or delirium.

After propensity score matching, no significant group difference was found in the demographic characteristics, surgical data, medications, or laboratory results (Table 1). Binary logistic regression of the propensity score-matched groups showed that significantly more patients with sarcopenia received postoperative blood transfusions than those without sarcopenia ( $\mathrm{OR}=6.60,95 \% \mathrm{Cl}: 1.57-45.5, p=0.021)$ (Table 2). 
The correlation between the SMI, reflecting whole-body muscle quantity, and postoperative blood transfusion was also explored in the propensity score-matched groups. Univariate receiver operating characteristic $(\mathrm{ROC})$ curve analysis was performed to determine the predictive accuracy of postoperative transfusion and the optimal cut-off value of the SMI. The ROC analysis suggested an SMI cut-off of 5.6 $\mathrm{kg} / \mathrm{m}^{2}$, with AUC value of $0.797(0.633-0.96)$, sensitivity of $66.7 \%$, and specificity of $86.2 \%$. (Figure 1 ).

\section{Discussion}

Sarcopenia is attracting attention as an independent predictor of postoperative morbidity and mortality. In arthroplasty, sarcopenia is associated with an increased risk of prosthetic infection after total hip or knee arthroplasty [35]. Patients with sarcopenia undergoing thoracolumbar spine surgery have an increased risk of postoperative complications and mortality, and significantly longer hospital stays [17]. Sarcopenia is also an independent risk factor for fragility fractures in all patients, and is responsible for the higher 1-year mortality rate of elderly sarcopenic patients with acetabular fractures $(28.6 \% \mathrm{vs} .12 .3 \%)$ $[36,37]$.

The correlations between sarcopenia and postoperative complications are becoming increasingly clear. Some studies have attempted to elucidate the correlation between sarcopenia and postoperative blood transfusion. Sarcopenia is thought to be associated with blood transfusions in head and neck cancer free-flap surgery [38]. Ardeljan et al. studied 90,438 patients who had undergone primary TKA; $16.7 \%$ of them had sarcopenia. The patients with sarcopenia had longer hospital stays and increased odds of falls, lower extremity fractures, reoperation, 2-year implant-related complications, surgery costs, and complications within 90 days, one of which was transfusion with blood products $(0.47 \%$ vs. $0.13 \%$, OR $=$ $4.24,95 \% \mathrm{Cl}: 3.09-5.82, p<0.0001)$ [29]. Our results are similar, in that patients with sarcopenia had a higher risk of postoperative blood transfusion than those without sarcopenia (OR $=6.60,95 \%$ Cl: $1.57-$ $45.5, p=0.021$ ), while there were no obvious correlations with postoperative AKI or delirium.

To our knowledge, no study has focused on muscle mass quantity as an important predictor of postoperative transfusion. Furthermore, no study has used BIA to evaluate sarcopenia. Here, we found a strong correlation between sarcopenia and postoperative transfusion, where more patients with sarcopenia had postoperative blood transfusions (28.6 vs. $12.2 \%$, OR $=2.87,95 \% \mathrm{Cl}: 1.25-6.17$, $p=0.009)$. After propensity-scored matching, sarcopenia continued to be a significant predictor of postoperative transfusion ( 28.6 vs. $5.7 \%, \mathrm{OR}=6.60,95 \% \mathrm{Cl}: 1.57-45.5, p=0.021)$. ROC curve analysis showed that the SMI, as a predictor of postoperative transfusion, had an area under the curve of 0.797 , sensitivity of $66.7 \%$, and specificity of $86.2 \%$, illustrating that the SMI discriminates well between transfused and non-transfused patients.

The pathophysiology of the increased rate of transfusions in sarcopenic patients remains unclear. However, it might be related to role of skeletal muscle as vascular reservoir with high capillary density compared to other soft tissues such as adipose tissue [38]. Because patients with sarcopenia have lower 
skeletal muscle mass, their total blood volume is also reduced and these patients might be more susceptible to blood loss [39].

Cross-sectional studies have revealed that knee osteoarthritis is associated with declines in muscle mass and strength in the lower limbs as the patient adapts to a sedentary lifestyle and inactivity to avoid knee pain and stiffness [40]. Since the majority of patients undergoing TKA have end-stage osteoarthritis, TKA patients may have a markedly decreased lower limb muscle mass, especially on the side requiring TKA. This supports the idea that a patient undergoing TKA is prone to sarcopenia, leading to more frequent postoperative blood transfusions.

One limitation of this study was the questionable validity of using multifrequency BIA to determine sarcopenia. Multifrequency BIA is widely accepted as a validated measure for assessing sarcopenia in European and Asian guidelines, and by the international research community studying cachexia $[21,25$, 41]. BIA is considered to have high concurrent validity for muscle mass estimation in normally hydrated and non-severely obese patients, making it feasible for evaluating low lean muscle mass and diagnosing sarcopenia [19]. The accuracy of BIA depends heavily on the adequacy of tissue hydration, and it should be used carefully in morbidly obese or overhydrated patients, as it can lead to overestimation of fat-free mass. Therefore, in our study, patients with an extracellular water ratio $>0.4$ and $\mathrm{BMI}>35 \mathrm{~kg} / \mathrm{m}^{2}$ were excluded to minimize the likelihood of muscle mass overestimation [30]. However, muscle mass may still have been somewhat overestimated, which might have led to the comparatively low incidence of sarcopenia compared to previous studies. Although there are consensus cut-off values for determining sarcopenia in Europe and Asia, populations of the same race may differ, so there is a need for populationspecific cut-offs for determining sarcopenia $[42,43]$.

We do not claim that BIA is a perfect tool for assessing sarcopenia; our aim was only to assess the use of BIA for screening sarcopenic patients undergoing orthopedic surgery, including TKA. For preoperative risk stratification of TKA patients, prospective studies including both muscle quantity and functional tests for sarcopenia are ed to find clear correlations between these tests and adverse outcomes of TKA patients. Functional testing may include gait speed, muscle grip strength, the get-up-and-go test, and peak expiratory flow [21]. Multifrequency BIA can serve as a screening tool for sarcopenia, as described here. Diagnoses of patients with low muscle mass at screening can then be confirmed, if necessary, via DEXA, which is the gold standard for quantifying muscle mass [25]. A long-term, retrospective review of the clinical outcomes of the sarcopenic patients in this cohort who underwent primary TKA, including postoperative pain, physical activity, and level of satisfaction, is ongoing. We hope to present the conclusions of this review in the near future.

Sarcopenia is a modifiable risk factor that can be prevented and managed [44, 45]. Evidence-based guidelines published by the American Medical Directors Association suggest that adequate protein intake and resistance exercises can enhance muscle strength [46]. Further studies should examine how to minimize the surgical complications of joint arthroplasty by identifying and adjusting modifiable risk factors, such as sarcopenia. 


\section{Conclusions}

In conclusion, among our patients undergoing primary TKA, 7.7\% were sarcopenic, and more of these patients received postoperative blood transfusions than non-sarcopenic patients. Orthopedic surgeons should be aware of this, as it could influence the decision-making process or treatment plan of patients with sarcopenia undergoing primary TKA.

\section{List Of Abbreviations}

TKA: Total Knee Arthroplasty

BIA: Bioelectrical impedance analysis

AKI: Acute Kidney Injury

SMI: Skeletal Muscle Index

AUC: Area Under Curve

DEXA: Dual-energy X-ray absorptiometry

BMI: Body Mass Index

TXA: tranexamic acid

mCCl: modified Charlson Comorbidity Index

ASA: American Society of Anesthesiologists

ROC: Receiver Operating Characteristic

\section{Declarations}

\section{Ethics approval and consent to participate}

As research involving human participants, this study has been performed in accordance with the ethical standards laid down in the 1964 Declaration of Helsinki and its later amendments, and has been approved by Seoul National University Hospital Institutional Review Board (IRB No. H-1806-185961). Exemption of informed consent was approved by Seoul National University Hospital Institutional Review Board. The authors certify that all methods were carried out in accordance with relevant guidelines and regulations that has been addressed in editorial policies of BioMed Central.

\section{Consent for publication}

Not applicable 
Availability of data and materials

All data generated or analysed during this study are included in this published article and its supplementary information files.

\section{Competing interests}

The authors declare that they have no competing interests.

\section{Funding}

This research was supported by Seoul National University College of Medicine Research Foundation (No. 800-20180538).

\section{Author's contributions}

$\mathrm{DH}$, the first and main author of this article, collected data, conducted statistical analysis, and was a major contributor in writing the manuscript. $\mathrm{HH}$, a co-author of this article, interpreted data to draw a solid conclusion, and revised the manuscript. ML, a co-author of this article, a co-author of this article, interpreted data to draw a solid conclusion, and revised the manuscript. DR, a corresponding author of this article, designed the study, interpreted data to draw a solid conclusion, and revised the manuscript at the final step. All authors read and approved the final manuscript. All are prepared to take public responsibility for the work and share responsibility and accountability for the results.

\section{Acknowledgements}

Not Applicable

\section{Authors' information (optional)}

Doohyun Hwang received B.S. degree in chemical and biological engineering and M.D. degree in medicine from Seoul National University, Seoul, South Korea in 2018 and 2022, respectively. His research interests include the impact of sarcopenia in orthopedic surgery, lower extremity malalignment, and deep learning algorithm for automatic segmentation/detection of musculoskeletal pathologies.

Hyuk-Soo Han received the M.D., M.S. and Ph.D. degrees in orthopedic surgery from Seoul National University, Seoul, South Korea, in 1997, 2004, and 2008, respectively. He is currently a Professor with the Department of Orthopedic Surgery, Seoul National University Hospital, Seoul. His research interests include cartilage regeneration, 3D printing, arthroplasty, and robotic surgery.

Myung Chul Lee received the M.D. and Ph.D. degrees in orthopedic surgery from Seoul National University, Seoul, South Korea, in 1983 and 1994, respectively. He is currently a Professor with the Department of Orthopedic Surgery, Seoul National University. His research interests include cartilage regeneration, osteotomy, arthroplasty, and sports medicine. 
Du Hyun Ro received the M.D., M.S. and Ph.D. degrees in orthopedic surgery from Seoul National University, Seoul, South Korea, in 2008, 2013, and 2020, respectively. He is currently an Assistant Professor with the Department of Orthopedic Surgery, Seoul National University Hospital, Seoul. His research interests include gait analysis, machine learning, sports medicine, and robotic surgery.

\section{References}

1. Stenquist DS, Elman SA, Davis AM, Bogart LM, Brownlee SA, Sanchez ES, et al. Physical activity and experience of total knee replacement in patients one to four years postsurgery in the dominican republic: a qualitative study. Arthritis Care Res (Hoboken). 2015;67(1):65-73.

2. Canovas F, Dagneaux L. Quality of life after total knee arthroplasty. Orthop Traumatol Surg Res. 2018;104(1S):S41-S6.

3. Chang MJ, Kim SH, Kang YG, Chang CB, Kim TK. Activity levels and participation in physical activities by Korean patients following total knee arthroplasty. BMC Musculoskelet Disord. 2014;15:240.

4. Inacio MCS, Paxton EW, Graves SE, Namba RS, Nemes S. Projected increase in total knee arthroplasty in the United States - an alternative projection model. Osteoarthritis Cartilage. 2017;25(11):1797-803.

5. Tan YC, Tan JY, Tsitskaris K. Systematic review: total knee arthroplasty (TKA) in patients with pigmented villonodular synovitis (PVNS). Knee Surg Relat Res. 2021;33(1):6.

6. Alshryda S, Mason J, Vaghela M, Sarda P, Nargol A, Maheswaran S, et al. Topical (intra-articular) tranexamic acid reduces blood loss and transfusion rates following total knee replacement: a randomized controlled trial (TRANX-K). J Bone Joint Surg Am. 2013;95(21):1961-8.

7. Deutsch A, Spaulding J, Marcus RE. Preoperative epoetin alfa vs autologous blood donation in primary total knee arthroplasty. J Arthroplasty. 2006;21(5):628-35.

8. Everhart JS, Sojka JH, Mayerson JL, Glassman AH, Scharschmidt TJ. Perioperative Allogeneic Red Blood-Cell Transfusion Associated with Surgical Site Infection After Total Hip and Knee Arthroplasty. J Bone Joint Surg Am. 2018;100(4):288-94.

9. Frisch NB, Wessell NM, Charters MA, Yu S, Jeffries JJ, Silverton CD. Predictors and complications of blood transfusion in total hip and knee arthroplasty. J Arthroplasty. 2014;29(9 Suppl):189-92.

10. Hart A, Khalil JA, Carli A, Huk O, Zukor D, Antoniou J. Blood transfusion in primary total hip and knee arthroplasty. Incidence, risk factors, and thirty-day complication rates. J Bone Joint Surg Am. 2014;96(23):1945-51.

11. Jo C, Ko S, Shin WC, Han HS, Lee MC, Ko T, et al. Transfusion after total knee arthroplasty can be predicted using the machine learning algorithm. Knee Surg Sports Traumatol Arthrosc. 2020;28(6):1757-64.

12. Lee JK, Lee KB, Kim Jl, Park GT, Cho YC. Risk factors for deep vein thrombosis even using lowmolecular-weight heparin after total knee arthroplasty. Knee Surg Relat Res. 2021;33(1):29. 
13. Adhikary SD, Liu WM, Memtsoudis SG, Davis CM, 3rd, Liu J. Body Mass Index More Than $45 \mathrm{~kg} / \mathrm{m}(2)$ as a Cutoff Point Is Associated With Dramatically Increased Postoperative Complications in Total Knee Arthroplasty and Total Hip Arthroplasty. J Arthroplasty. 2016;31(4):749-53.

14. Lubbeke A, Zingg M, Vu D, Miozzari HH, Christofilopoulos P, Uckay I, et al. Body mass and weight thresholds for increased prosthetic joint infection rates after primary total joint arthroplasty. Acta Orthop. 2016;87(2):132-8.

15. Cheuy VA, Foran JRH, Paxton RJ, Bade MJ, Zeni JA, Stevens-Lapsley JE. Arthrofibrosis Associated With Total Knee Arthroplasty. J Arthroplasty. 2017;32(8):2604-11.

16. Delmonico MJ, Beck DT. The Current Understanding of Sarcopenia: Emerging Tools and Interventional Possibilities. Am J Lifestyle Med. 2017;11(2):167-81.

17. Bokshan SL, Han AL, DePasse JM, Eltorai AE, Marcaccio SE, Palumbo MA, et al. Effect of Sarcopenia on Postoperative Morbidity and Mortality After Thoracolumbar Spine Surgery. Orthopedics. 2016;39(6):e1159-e64.

18. Beaudart C, McCloskey E, Bruyere O, Cesari M, Rolland Y, Rizzoli R, et al. Sarcopenia in daily practice: assessment and management. BMC Geriatr. 2016;16(1):170.

19. Gonzalez MC, Barbosa-Silva TG, Heymsfield SB. Bioelectrical impedance analysis in the assessment of sarcopenia. Curr Opin Clin Nutr Metab Care. 2018;21(5):366-74.

20. Lang JZ, Wu CC, Jin JF, Wu P, Hen L. [Analysis of influence of sarcopenia on early postoperative function of femoral neck fracture by hip arthroplasty]. Zhongguo Gu Shang. 2018;31(9):835-9.

21. Chen LK, Woo J, Assantachai P, et al. Asian Working Group for Sarcopenia: 2019 Consensus Update on Sarcopenia Diagnosis and Treatment. J Am Med Dir Assoc. 2020 Mar;21(3):300-307.e2.

22. Chen LK, Liu LK, Woo J, Assantachai P, Auyeung TW, Bahyah KS, et al. Sarcopenia in Asia: consensus report of the Asian Working Group for Sarcopenia. J Am Med Dir Assoc. 2014;15(2):95101.

23. McLean RR, Shardell MD, Alley DE, Cawthon PM, Fragala MS, Harris TB, et al. Criteria for clinically relevant weakness and low lean mass and their longitudinal association with incident mobility impairment and mortality: the foundation for the National Institutes of Health (FNIH) sarcopenia project. J Gerontol A Biol Sci Med Sci. 2014;69(5):576-83.

24. Heymsfield SB, Gonzalez MC, Lu J, Jia G, Zheng J. Skeletal muscle mass and quality: evolution of modern measurement concepts in the context of sarcopenia. Proc Nutr Soc. 2015;74(4):355-66.

25. Cruz-Jentoft AJ, Bahat G, Bauer J, Boirie Y, Bruyere O, Cederholm T, et al. Sarcopenia: revised European consensus on definition and diagnosis. Age Ageing. 2019;48(1):16-31.

26. Friedman J, Lussiez A, Sullivan J, Wang S, Englesbe M. Implications of sarcopenia in major surgery. Nutr Clin Pract. 2015;30(2):175-9.

27. Bokshan SL, DePasse JM, Daniels AH. Sarcopenia in Orthopedic Surgery. Orthopedics. 2016;39(2):e295-300. 
28. Kohli K, Corns R, Vinnakota K, Steiner P, Elith C, Schellenberg D, et al. A bioimpedance analysis of head-and-neck cancer patients undergoing radiotherapy. Curr Oncol. 2018;25(3):e193-e9.

29. Ardeljan AD, Polisetty TS, Palmer J, Vakharia RM, Roche MW. Comparative Analysis on the Effects of Sarcopenia following Primary Total Knee Arthroplasty: A Retrospective Matched-Control Analysis. J Knee Surg. 2020.

30. Aleixo GFP, Shachar SS, Nyrop KA, Muss HB, Battaglini CL, Williams GR. Bioelectrical Impedance Analysis for the Assessment of Sarcopenia in Patients with Cancer: A Systematic Review. Oncologist. 2020;25(2):170-82.

31. Jang S, Shin WC, Song MK, Han HS, Lee MC, Ro DH. Which orally administered antithrombotic agent is most effective for preventing venous thromboembolism after total knee arthroplasty? A propensity score-matching analysis. Knee Surg Relat Res. 2021;33(1):10.

32. Lakomkin N, Zuckerman SL, Stannard B, Montejo J, Sussman ES, Virojanapa J, et al. Preoperative Risk Stratification in Spine Tumor Surgery: A Comparison of the Modified Charlson Index, Frailty Index, and ASA Score. Spine (Phila Pa 1976). 2019;44(13):E782-E7.

33. Ko S, Jo C, Chang CB, Lee YS, Moon YW, Youm JW, et al. A web-based machine-learning algorithm predicting postoperative acute kidney injury after total knee arthroplasty. Knee Surg Sports Traumatol Arthrosc. 2020.

34. Janjua MS, Spurling BC, Arthur ME. Postoperative Delirium. StatPearls. Treasure Island (FL)2021.

35. Babu JM, Kalagara S, Durand W, Antoci V, Deren ME, Cohen E. Sarcopenia as a Risk Factor for Prosthetic Infection After Total Hip or Knee Arthroplasty. J Arthroplasty. 2019;34(1):116-22.

36. Tarantino U, Piccirilli E, Fantini M, Baldi J, Gasbarra E, Bei R. Sarcopenia and fragility fractures: molecular and clinical evidence of the bone-muscle interaction. J Bone Joint Surg Am. 2015;97(5):429-37.

37. Deren ME, Babu J, Cohen EM, Machan J, Born CT, Hayda R. Increased Mortality in Elderly Patients with Sarcopenia and Acetabular Fractures. J Bone Joint Surg Am. 2017;99(3):200-6.

38. Jones AJ, Campiti VJ, Alwani M, Novinger LJ, Tucker BJ, Bonetto A, et al. Sarcopenia is associated with blood transfusions in head and neck cancer free flap surgery. Laryngoscope Investig Otolaryngol. 2021;6(2):200-10.

39. Prior SJ, Ryan AS, Blumenthal JB, Watson JM, Katzel LI, Goldberg AP. Sarcopenia Is Associated With Lower Skeletal Muscle Capillarization and Exercise Capacity in Older Adults. J Gerontol A Biol Sci Med Sci. 2016;71(8):1096-101.

40. Ho KK, Lau LC, Chau WW, Poon Q, Chung KY, Wong RM. End-stage knee osteoarthritis with and without sarcopenia and the effect of knee arthroplasty - a prospective cohort study. BMC Geriatr. 2021;21(1):2.

41. Blum D, Stene GB, Solheim TS, Fayers P, Hjermstad MJ, Baracos VE, et al. Validation of the Consensus-Definition for Cancer Cachexia and evaluation of a classification model-a study based on data from an international multicentre project (EPCRC-CSA). Ann Oncol. 2014;25(8):1635-42. 
42. Bahat G, Tufan A, Kilic C, Karan MA, Cruz-Jentoft AJ. Methodological issues in determination of low muscle mass reference cut-off values: Reply to Comment on "Cut-off points to identify sarcopenia according to European Working Group on Sarcopenia in Older People (EWGSOP) definition". Clin Nutr. 2017;36(3):903-4.

43. Zeng P, Wu S, Han Y, Liu J, Zhang Y, Zhang E, et al. Differences in body composition and physical functions associated with sarcopenia in Chinese elderly: reference values and prevalence. Arch Gerontol Geriatr. 2015;60(1):118-23.

44. Morley JE. Sarcopenia: diagnosis and treatment. J Nutr Health Aging. 2008;12(7):452-6.

45. Morley JE, Argiles JM, Evans WJ, Bhasin S, Cella D, Deutz NE, et al. Nutritional recommendations for the management of sarcopenia. J Am Med Dir Assoc. 2010;11(6):391-6.

46. Morley JE, Anker SD, von Haehling S. Prevalence, incidence, and clinical impact of sarcopenia: facts, numbers, and epidemiology-update 2014. J Cachexia Sarcopenia Muscle. 2014;5(4):253-9.

\section{Figures}




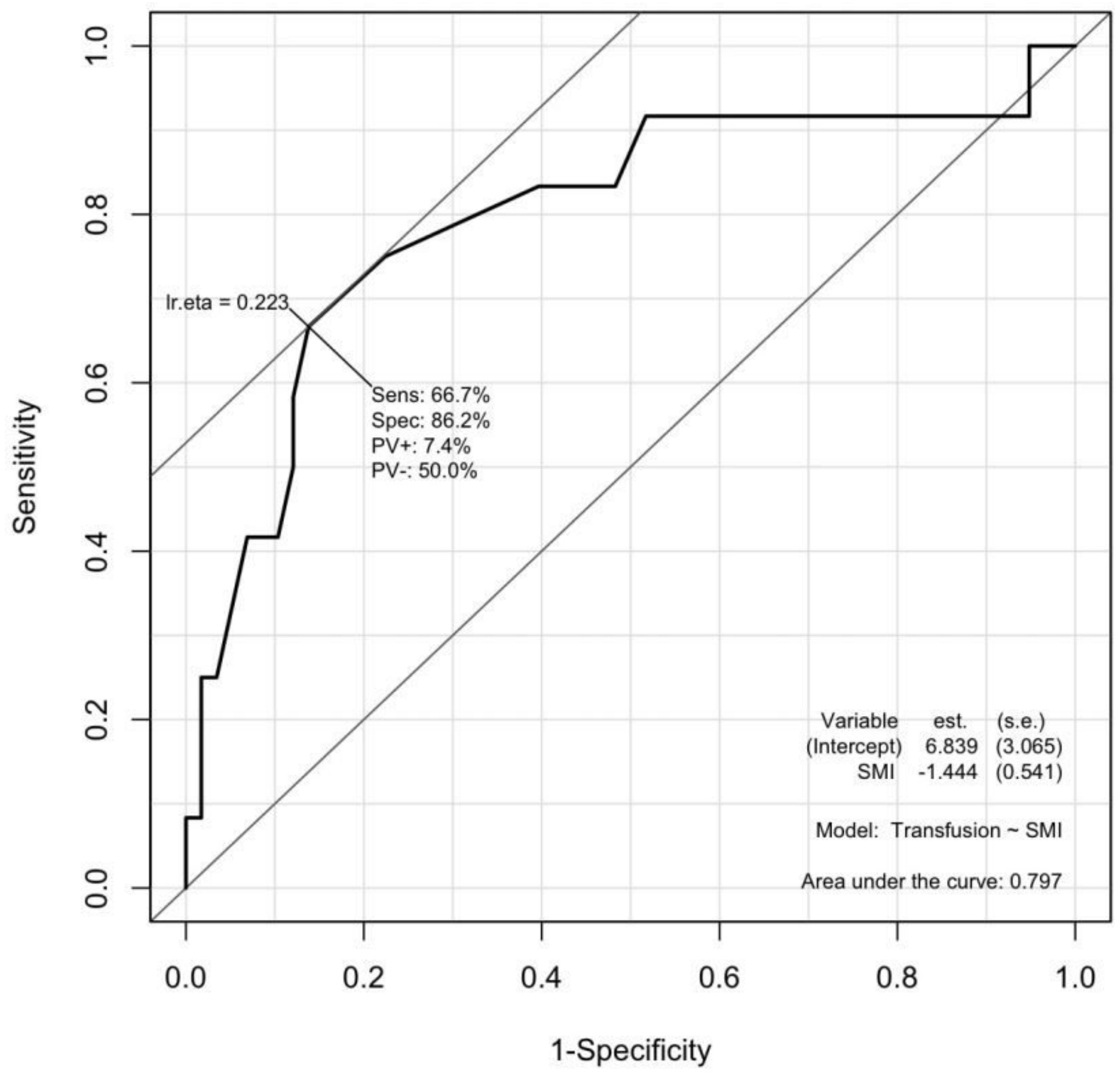

Figure 1

Area under the receiver operating curve from univariate analysis showing the capacity of SMI to predict postoperative transfusion.

\section{Supplementary Files}


This is a list of supplementary files associated with this preprint. Click to download.

- Additionalfile1.docx 